\title{
DEFINIÇÕES DE PONTOS CRANIOMÉTRICOS EM IMAGENS MULTIPLANARES DE RESSONÂNCIA MAGNÉTICA (RM) PARA FINS DE RECONSTRUÇÃO FACIAL FORENSE
}

\author{
CRANIOMETRIC LANDMARKS DEFINITIONS FROM MULTIPLANAR MAGNETIC RESONANCE \\ IMAGES (MRI) REGARDING FORENSIC FACIAL RECONSTRUCTION
} Welson D. F. dos Santos ${ }^{1}$, Paula R. B. Diniz², Antonio C. Santos²,
Carmen C. S. Martin'1, Marco A. Guimarães ${ }^{1}$

\begin{abstract}
${ }^{1}$ Pós graduando, Centro de Medicina Legal, Departamento de Patologia. ${ }^{2}$ Pós-graduanda, Centro de Imagens e Física Médica. ${ }^{3}$ Docente, Centro de Imagens e Física Médica, Hospital das Clínicas da FMRP-USP, Departamento de Clínica Médica. ${ }^{4}$ Docente. Centro de Medicina Legal, Departamento de Patologia. Faculdade de Medicina de Ribeirão Preto - USP.

CorrespondÊncIA: Dr. Marco Aurelio Guimarães. Centro de Medicina Legal (CEMEL). Departamento de Patologia. Faculdade de Medicina de Ribeirão Preto - USP. Rua Tenente Catão Roxo n² 2418. 14051-140 - Ribeirão Preto - SP. Brasil.

Tel.: +55-16-36023358; fax: +55-16-36334476. E-mail: mag@fmrp.usp.br
\end{abstract}

Santos WDF, Diniz PRB, Santos AC, Martin CCS, Guimarães MA. Definições de pontos craniométricos em imagens multiplanares de Ressonância Magnética (RM) para fins de reconstrução facial forense. Medicina (Ribeirão Preto) 2008; 41 (1): 17-23.

RESUMO: A reconstrução facial pode ser uma ferramenta útil dentro do processo de identificação médico-legal. O método tem apresentado uma evolução contínua ao longo dos anos, tornando-se mais acurado. A sua fidelidade deve-se em parte as medidas de tecidos moles que são empregadas para se reconstituir o rosto a partir de um crânio. A proposta deste estudo foi a de investigar e conhecer dados sobre a correta localização e definição de 22 pontos craniométricos estabelecidos na literatura a partir de estruturas anatômicas e adaptá-los para imagens obtidas em exames digitais de ressonância magnética (RM), de forma a permitir a futura mensuração da espessura dos tecidos moles crânio-faciais de brasileiros vivos com alta precisão e confiabilidade. Ficou evidenciada a necessidade de mudança na forma de localizar as referências anatômicas ósseas e seus correspondentes em tecidos moles, especialmente em três pontos, onde o conhecimento detalhado de anatomia dental é requerido. O estabelecimento dessas definições poderá fundamentar as bases da elaboração de uma tabela antropomórfica contendo as espessuras de tecidos moles da face de brasileiros com vista à aplicação em reconstituição facial forense, para preencher esta lacuna do conhecimento médico-legal no Brasil.

Descritores: Medicina Legal. Pontos Craniométricos. Tecidos Moles. Face. Reconstrução Facial.

\section{1- INTRODUÇÃO}

A reconstrução ou reconstituição facial é um método que, em Medicina Legal, propicia a ocorrência do reconhecimento, podendo incrementar as chances de que familiares venham a dar indícios que direcionem a investigação pormenorizada da real iden- tidade associada a determinados restos mortais sem identificação ${ }^{1}$.

Nas Ciências Forenses deve-se fazer distinção entre o processo de reconhecimento e o de identificação humana. $\mathrm{O}$ também denominado reconhecimento médico-legal é o procedimento que precede a etapa de identificação, visando prioritariamente à diminui- 
ção do número de sujeitos suspeitos. O reconhecimento pode ser passo precedente essencial ao processo de identificação. Enquanto o reconhecimento é um procedimento de fundo subjetivo, pois depende de uma terceira pessoa verificar uma determinada informação não baseada em dados científicos, a identificação fundamenta-se no estabelecimento da identidade com base em dados objetivos tidos como cientificamente válidos para determinação de uma identidade.

Quase todos os atos da vida humana baseiam-se no reconhecimento de pessoas e coisas, sendo que a identificação de pessoas pode ser feita nos vivos e nos mortos ${ }^{2}$. Nesses casos, onde não há mais a vida, deve-se priorizar o objetivo de se chegar a uma identificação do cadáver.

O reconhecimento ajuda a eliminar outros prováveis suspeitos, além de estimular a memória de testemunhas, uma vez que o reconhecimento, em grande parte das vezes, é focado nas características da face das pessoas ${ }^{3}$. Em estudo relativo à percepção psicológica da face ${ }^{4}$, evidenciou-se que apresentamos limitações em descrever rostos não-familiares, mas a capacidade de reconhecimento de faces de pessoas conhecidas é tida como evidente, mesmo que as imagens disponíveis para se fazer o reconhecimento apresentem distorções.

A reconstrução facial pode ser uma ferramenta útil nesse processo, sendo que o método vem apresentado uma evolução permanente ao longo dos anos. A reconstituição da face, quando associada a outras informações para identificação, como exame antropológico, de sinais individuais, dos arcos dentais, de radiografias, além de exames de DNA, pode contribuir favoravelmente para o processo de reconhecimento e identificação humana ${ }^{5}$.

Inicialmente, a reconstrução facial havia sido realizada apenas artisticamente, reproduzindo sobre o crânio seco os aspectos do tecido mole perdido. Em momento posterior, começou a ser utilizada a superposição de imagens fotográficas ou de vídeo, comparando o crânio seco com a imagem da pessoa suspeita em sua pré-morte ${ }^{6}$.

Recentemente, a literatura consultada aponta avanços na área da informática que são aplicados no método de reconhecimento médico-legal ${ }^{7}$. Estes recentes progressos remetem-se à utilização da reconstrução facial tridimensional(3D), que colabora para se atingir resultados mais precisos. Esta técnica está atualmente baseada em medidas de tecidos moles provenientes de bancos de dados originários de imagens multiplanares de exames de tomografia computadorizada ${ }^{8}$.
Entretanto, por maiores avanços que se tenham no campo tecnológico, é importante ressaltar que os dados que vão alimentar os programas de computador e/ou mesmo orientar reconstruções artesanais, estão baseados em diferentes espessuras e profundidades dos tecidos moles do esqueleto crânio-facial originários de populações distintas da brasileira ${ }^{9}$. A literatura apresenta uma lacuna no que tange a medidas de tecidos moles para reconstruções faciais forenses para indivíduos de nacionalidade brasileira.

Todas as propostas envolvendo estudos de métodos de reconstrução facial apontam para a necessidade de criar condições de levantar dados compatíveis com indivíduos vivos, pertencentes a uma população específica, para que possam ser aplicados de forma mais precisa no processo de reconhecimento médico-legal ${ }^{3}$.

Neste processo, existe a possibilidade da ocorrência de erros por ocasião da coleta das medidas de profundidade dos tecidos moles das diferentes regiões superficiais da face até seus respectivos pontos ósseos, os denominados pontos craniométricos. As informações existentes e até então utilizadas, são em grande parte, oriundas de mensurações realizadas em cadáveres, o que gera distorções, seja pela desidratação do corpo, seja pela técnica de embalsamamento, além dos casos de corpos putrefeitos ${ }^{1}$.

Constatado esse vazio de informação no campo antropomórfico nacional, torna-se necessário mapear e estabelecer a correta localização e definição de pontos craniométricos padronizados, equivalentes aos disponíveis na literatura internacional, com a maior precisão possível, de forma a permitir a mensuração da espessura dos tecidos moles crânio-faciais de brasileiros vivos, com vista à adequada padronização dos elementos que envolvem a reconstrução facial forens ${ }^{10}$.

Nesse sentido, optou-se pela utilização de exames de Ressonância Magnética (RM), utilizados em diagnóstico médico intra-hospitalar, por várias razões: este tipo de exame não gera radiação ionizante, apresenta maior qualidade na formação e visualização da imagem de tecidos moles, bem como permite a associação de recursos e ferramentas computacionais que favorecem a realização dessas medidas.

Isto poderá acrescentar maior objetividade na realização de reconstituições faciais necessárias nos processos de reconhecimento e identificação médico-legal, tendo em vista a grande incidência de mortes violentas, em especial na cidade de Ribeirão Preto e região, onde é comum a descoberta de casos de ossadas que são abandonadas ou enterradas clandestinamente ${ }^{11}$. 
Assim, o objetivo deste trabalho foi localizar e definir, em exames de RM, 22 pontos craniométricos a serem utilizados na realização de reconstruções faciais para fins forenses, de forma a permitir a futura validação de método envolvendo a mensuração de tecidos moles da face de indivíduos vivos, o que possibilitará a criação de tabela de medidas de espessura de tecidos moles da face de brasileiros vivos.

\section{2- MATERIAL E MÉTODOS}

Utilizando-se exames digitais de RM e o programa de computador E-film ${ }^{12}$, que permite a realização de medidas lineares de espessura de tecidos moles, foram realizadas análises da anatomia presente nas imagens para estabelecer propostas de definições e respectivas localizações de 22 pontos craniométricos compatíveis com a literatura internacional. As bases para esta seleção vieram de referências especializadas em reconstrução facial para fins forenses, mas que utilizaram medidas com fundamentação anatômica, na sua maioria, a partir de cadáveres, sendo necessária a sua adaptação para a anatomia imagenológica de exames de RM de pessoas vivas.

Foram utilizados exames de RM do crânio, onde tecidos moles da região facial de pacientes adultos, do sexo masculino, sem distorções congênitas ou adquiridas, pudessem ser avaliados. Essas imagens são provenientes do Centro de Imagens e Física Médica do Hospital das Clínicas da FMRP-USP.

Metade dos 22 pontos selecionados está situada sobre a linha média. Os demais 11 pontos são bilaterais, localizados simetricamente no lado direito e esquerdo da face. Portanto, 33 pontos foram utilizados para fins de definição anatômica em RM para guiar as futuras mensurações de tecidos moles faciais e evitar a ocorrência de possíveis distorções anatômicas em lateralidade.

Esse estudo teve a aprovação do Comitê de Ética em Pesquisa institucional (processo: HCRP 11.568/2003).

\section{3- RESULTADOS E DISCUSSÃO}

Por questão de praticidade, imagens de cada ponto individualmente não são apresentadas. A figura 1 exemplifica o estabelecimento de um único ponto craniométrico. A seguir é apresentada a definição dos 22 pontos craniométricos (11 na linha média e 11 bilaterais) selecionados, com sua descrição tradicional anatômica e sua definição para utilização em RM. Os dados são apresentados nas Tabelas I e II.

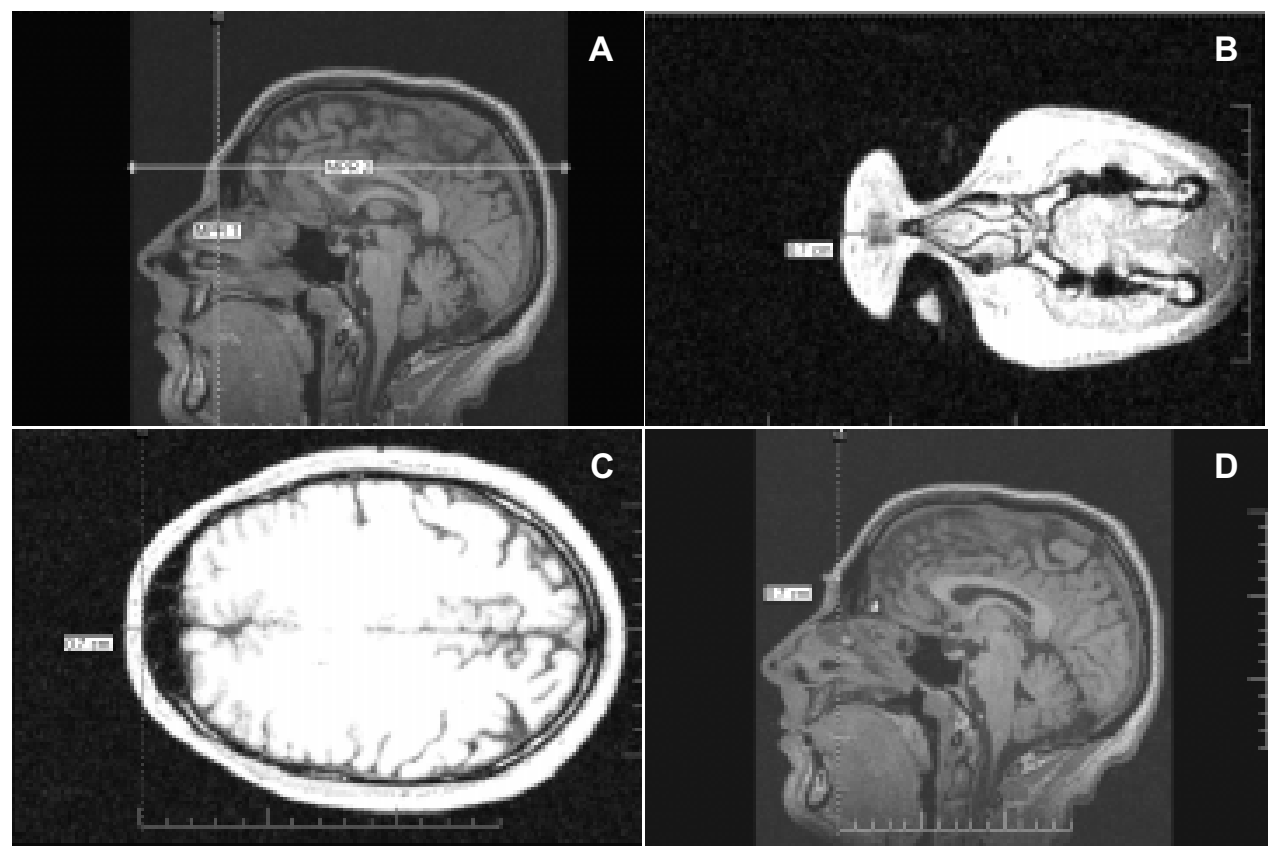

Figura 1: Diferentes cortes de exames de RM e ferramenta do programa de computador (E-Film), que permite a localização e mensuração da espessura de tecidos moles. Notar a exemplificação do ponto da glabela (P2- ver Tabela I). A) Intersecção das retas evidenciando a localização do ponto craniométrico a ser medido; B, C e D - respectivamente imagens dos planos coronal, axial e sagital. Estas imagens permitem a confirmação multiplanar da localização do ponto craniométrico, bem como da medida de espessura de tecidos moles no seu correspondente anatômico. 


\section{Tabela I: Denominação, descrição anatômica e localização em imagens multiplanares de RM dos pontos craniomé-} tricos de 0 a 11 situados na linha média.

\begin{tabular}{|c|c|c|}
\hline Ponto & Denominação & Descrição anatômica e localização em imagens multiplanares de RM \\
\hline 0 & Trichion & $\begin{array}{l}\text { Localizado e medido a partir de imagem de corte sagital, na superfície externa } \\
\text { do osso frontal, no ponto mais superior e anterior, correspondendo aproxi- } \\
\text { madamente à linha de implantação dos cabelos. }\end{array}$ \\
\hline 1 & Supraglabela & $\begin{array}{l}\text { Localizado e medido a partir de imagem de corte sagital, na superfície externa } \\
\text { do osso frontal, acima da glabela, no ponto mais profundo da depressão } \\
\text { entre as convexidades máximas das eminências frontais. }\end{array}$ \\
\hline 2 & Glabela & $\begin{array}{l}\text { Localizado e medido a partir de imagem de corte sagital, no local de maior } \\
\text { convexidade apresentada pela superfície externa do osso frontal, na sua } \\
\text { região inferior, logo acima das suturas fronto-nasais. }\end{array}$ \\
\hline 3 & Nasio & $\begin{array}{l}\text { Localizado e medido a partir de imagem de corte sagital, no ponto localizado } \\
\text { na porção mais côncava da região da sutura fronto-nasal correspondente à } \\
\text { deflexão do tecido mole da região frontal e nasal. A confirmação deve ser } \\
\text { feita utilizando o último corte axial antes de aparecer imagem de osso nasal. }\end{array}$ \\
\hline 4 & $\begin{array}{l}\text { Rinio ou final } \\
\text { do osso nasal }\end{array}$ & $\begin{array}{l}\text { Localizado a partir de imagem de corte sagital no ponto mais inferior e ante- } \\
\text { rior dos ossos nasais sobre a sutura inter-nasal, a fusão entre os ossos } \\
\text { nasais é a referência que pode ser utilizada para a confirmação da exata } \\
\text { localização, sendo visualizada no corte axial. Em tecido mole a correspon- } \\
\text { dência é a junção óssea-cartilaginosa. Ambos os planos de corte axial e } \\
\text { sagital podem ser utilizados para a medida. }\end{array}$ \\
\hline 5 & Filtro-médio & $\begin{array}{l}\text { Também denominado de sub-espinhal, situado na porção mais inferior da } \\
\text { crista óssea que origina a espinha nasal anterior, visualizada no corte axial, } \\
\text { tem como seu correspondente em tecido mole o ponto médio da coluna do } \\
\text { filtro, verificado no corte sagital, local onde deve ser realizado a mensuração. }\end{array}$ \\
\hline 6 & $\begin{array}{l}\text { Margem do lábio } \\
\text { superior }\end{array}$ & $\begin{array}{l}\text { Localizado e medido a partir de imagem de corte sagital, esse ponto também } \\
\text { é denominado de Prostion, situado anteriormente no rebordo alveolar da } \\
\text { maxila entre os dentes incisivos centrais, sendo o tubérculo do lábio superior } \\
\text { seu correspondente de tecido mole. }\end{array}$ \\
\hline 7 & Margem do lábio inferior & $\begin{array}{l}\text { Localizado e medido a partir de imagem de corte sagital, esse ponto também } \\
\text { é denominado de Infradental, situado anteriormente no rebordo alveolar da } \\
\text { mandíbula entre os dentes incisivos centrais, sendo o tubérculo do lábio } \\
\text { inferior seu correspondente de tecido mole. }\end{array}$ \\
\hline 8 & Supramental & $\begin{array}{l}\text { Situado na parte mais profunda da concavidade existente na região anterior } \\
\text { e inferior do corpo da mandíbula, sendo a parte mais profunda da prega } \\
\text { labiomental seu correspondente de tecido mole. }\end{array}$ \\
\hline 9 & Eminência mental & $\begin{array}{l}\text { Localizado e medido a partir de imagem de corte sagital, é também denomina- } \\
\text { do de Pogônio, situado no ponto mais anterior da curvatura da protuberância } \\
\text { mentoniana, podendo ser confirmada a localização e mensuração em imagem } \\
\text { do corte axial, que evidencie a imagem de maior convexidade da cortical } \\
\text { óssea mandibular vestibular. }\end{array}$ \\
\hline 10 & Gnatio & $\begin{array}{l}\text { Localizado e medido a partir de imagem de corte sagital é o ponto mandibular } \\
\text { mais inferior localizado sobre a linha média, a exata localização e medida } \\
\text { podem ser confirmadas com imagem do corte coronal. }\end{array}$ \\
\hline
\end{tabular}


Tabela II: Denominação, descrição anatômica e localização em imagens multiplanares de RM dos pontos craniométricos de 11 a 21 situados bilateralmente.

Ponto Denominação $\quad$ Descrição anatômica e localização em imagens multiplanares de RM

11 Eminência Frontal

12

Orbital superior

Orbital inferior

14

15

16

17

18

19

20
Lateral da órbita ou zigomático-orbital

\section{Zigomático inferior ou} malar inferior

zigomático-orbital

6 Meio do arco Zigomático

17 Supraglenoide

Goníaco

Supra segundo molar superior

Supra segundo molar inferior
Na porção mais superior e proeminente da região lateral do osso frontal, observado e mensurado no corte sagital. O centro da pupila é a referência para guiar o plano de corte.

Região lateral inferior do osso frontal no ponto médio da margem orbital superior, observado e mensurado no corte sagital, sendo a supercílio o seu correspondente em tecido mole e o centro da pupila a referência para guiar o plano de corte.

No ponto médio da margem infra-orbital do osso zigomático, observado e mensurado no corte sagital.

Ponto situado na parte mais profunda anterior e inferior do osso maxilar na junção do processo alveolar (superiormente) com a base do pilar zigomático (medialmente), visto em corte axial, e tendo como correspondente a imagem que evidencie o vértice inferior do seio maxilar no corte sagital, onde deve ser mensurado.

Ponto de intersecção da linha que tangencia a margem lateral da órbita com a região de máxima convexidade do osso zigomático, visto e mensurado no corte axial; confirmado pelas imagens em corte sagital e coronal, corresponde ao local da sutura zigomático-maxilar.

Localizado sobre a região mais lateral da superfície externa do arco zigomático, visualizado e medido no corte axial, confirmada pela imagem do corte coronal correspondente.

Localizado e medido no corte axial, na porção mais distal do arco zigomático, logo acima da cavidade glenóidea, tendo como referência a imagem da cápsula articular do côndilo da mandíbula, também visualizada no corte coronal.

Localizado e medido sobre o corte axial na parte mais inferior e posterior do ângulo mandibular, entre o ramo e o corpo, onde as paredes vestibular e lingual se fundem. Em correspondência, o corte sagital deve evidenciar imagem da porção inferior do ramo em forma de um vértice.

Sobre a região mais lateral da superfície externa da margem alveolar da maxila, geralmente próximo à região cervical da coroa do segundo molar superior. O corte sagital deve identificar a presença do segundo molar, enquanto o corte axial favorece tanto a confirmação visual desta referência anatômica dental, como a mensuração desejada.

Localizado sobre a face lateral do ramo mandibular na intersecção da continuação da linha oclusal com a linha vertical paralela ao processo coronóide da mandíbula que divida o ramo da mandíbula ao meio, na vertical. A localização e mensuração deste ponto devem ser feitas utilizando o corte axial exatamente no ponto de máxima constrição das corticais vestibular e lingual do ramo mandibular.

Situado sobre a região mais lateral da superfície externa da margem alveolar da mandíbula, freqüentemente próximo à região cervical da coroa do segundo molar inferior. O corte sagital deve identificar a presença do segundo molar, enquanto o corte axial favorece tanto a confirmação visual desta referência anatômica dental, como a mensuração desejada. 
A priori, as medidas de espessura de tecidos moles para fins de reconstrução facial forense devem permitir que diferentes executores possam criar reconstruções semelhantes de uma mesma face. Contudo, pode-se afirmar que medidas realizadas a partir de mensurações envolvendo os pontos craniométricos de referência e até então definidos, localizados e apresentados a partir de conhecimento calcado apenas na anatomia física de cadáveres é uma metodologia muito distinta daquela envolvendo imagens multiplanares de RM.

A técnica associada a imagens de RM permite aumentar a precisão das medidas e conseqüentemente propiciar um banco de dados mais fiel da espessura de tecidos moles que envolvem os pontos anatômicos tidos como referência para as diferentes técnicas de reconstrução facial existentes. Contudo, essas medidas só serão validas se os pontos que permitem sua medida estiverem definidos e localizados de forma clara e objetiva.

Durante o processo de localização e definição dos pontos selecionados, utilizou-se imagens de RM e buscou-se seguir a orientação anatômica básica sugerida e apontada pela literatura, mantendo-se aproximadamente as definições anatômicas ósseas originais em vários pontos craniométricos estudados $\mathrm{e}$ acrescentando-se as necessárias informações envolvendo os tecidos moles. Lembra-se que tais pontos podem ser acessados nos planos axial, coronal e sagital provenientes das imagens multiplanares de RM (Figura 1).

Com o propósito de preservar a eficiência e eficácia do método, dentre os vinte e dois pontos, três necessitaram de mudança na descrição da localização de referências anatômicas ósseas e seus correspondentes em tecidos moles: P7 - Margem do Lábio Inferior; P14 - Malar Inferior e P19 - Supra Segundo Molar Superior, bilateralmente (Tabelas I e II).

A provável explicação para isto está no fato de que os pontos apontados envolvem a necessidade de conhecimento mais detalhado da anatomia dental para a sua correta localização sobre a superfície óssea da região. Nos pontos destacados, a presença de incisivos centrais e segundos molares superiores e inferiores é fundamental para o estabelecimento da sua correta e precisa localização imagenológica.

O estabelecimento das definições apresentadas neste trabalho já permitiu o início da coleta de dados de medidas de tecidos moles da face de brasileiros vivos. A validação dos dados coletados permitirá a elaboração de uma tabela de medidas do padrão antropomórfico brasileiro de forma a viabilizar a execução de diferentes técnicas de reconstrução facial de forma mais precisa e correta, considerando-se o padrão diferenciado da face dos brasileiros, cuja origem étnica é bastante miscigenada.

\section{4- CONCLUSÃO}

Conclui-se que o estabelecimento das definições dos pontos craniométricos em imagens multiplanares de RM é passo essencial para a correta utilização desta metodologia para a obtenção de dados que garantam objetividade e confiabilidade nas diferentes técnicas de reconstituição facial forense para a população brasileira.

Santos WDF, Diniz PRB, Santos AC, Martin CCS, Guimarães MA. Craniometric landmarks definitions from multiplanar Magnetic Resonance Images (MRI) regarding forensic facial reconstruction. Medicina (Ribeirão Preto) 2008; 41 (1): 17-23.

ABSTRACT: Facial reconstruction can be a useful tool in the process of medico-legal identification. The method has presented a continuous evolution through the years, becoming more accurate. Its reliability is, in part, due to the facial soft tissues measurements that are applied to reconstruct a face from a skull. The aim of this study was investigating and knowing data about the correct localization and definitions of 22 craniometric landmarks established in the literature from anatomical structures and adapt them to images obtained from digital exams of magnetic resonance imaging (MRI), allowing the future measurements of cranio-facial soft tissues thickness of living Brazilians with high precision and reliability. It was evidenced the necessity of changing the localization methods of bone anatomical references and their soft tissues correspondents, especially in three landmarks, where detailed knowledge about dental anatomy is required. The establishment of these definitions will give support to the setting of an anthropomorphic table containing the facial soft tissues thickness of Brazilians regarding their utilization in forensic facial reconstruction, to fill this gap in the Brazilian medico-legal knowledge.

Key-words: Forensic Medicine. Craniometric Landmarks. Soft Tissues. Face. Facial Reconstruction. 


\section{5- AGRADECIMENTOS}

À Coordenação de Aperfeiçoamento de Pessoal de Nível Superior (CAPES), pelo apoio financeiro. À Rita de Fátima Aprobato, do Centro de Imagens e Física Médica do Hospital das Clínicas da FMRPUSP, pelo auxílio ao acesso às imagens de RM.

\section{6- REFERÊNCIAS}

1 - Nelson LA, Michael SD. The application of volume deformation to three-dimensional facial reconstruction: a comparison with previous techniques. Forensic Sci Int 1998; 94(3): 167-81

2 - Carvalho HV. Lições de medicina legal. 2nd. ed. São Paulo: Secretaria da Segurança Pública; 1963.

3 - Tyrrell AJ, Evison MP, Chamberlain AT, Green MA. Forensic three-dimensional facial reconstruction: historical review and contemporary developments. J Forensic Sci 1997; 42(4): 653-61.

4 - Bruce V, Young AW. Understanding face recognition. Br J Psychol 1986; 77(Pt3): 305-27.

5 - Evison MP. Virtual 3-D facial reconstruction. Internet Archaeology 2000. Available from:http://intarch.ac.uk/ journal/issue8.

6 - Aulsebrook WA, Iscanb MY, Slabbert JH. Beckerd P. Superimposition and reconstruction in forensic facial identification: a survey. Forensic Sci Int 1995; 75 (2/3): 10120
7 - De Greef S, Willems G. Three-dimensional cranium-facial reconstruction in forensic identification: Latest progress and new tendencies in the 21st century. J Forensic Sci 2005; 50(1): $12-7$.

8 - Kim, KD, Ruprecht A, Wang G, Lee JB, Dawson DV, Vannier MW. Accuracy of facial soft tissue thickness measurements in personal computer-based multiplanar reconstructed computed tomography images. Forensic Sci Int 2005; 155(1): 28-34.

9 - Rhine JS, Moore, CE. Reproduction tables of facial tissue thickness of American Caucasoid. In: Rhine JS, Moore, CE, editors. Forensic anthropology. Albuquerque: Maxwell Museum; 1984. (Technical Series 1)

10 - Cattaneo C. Forensic anthropology: developments of a classical discipline in the next millennium. Forensic Sci Int 2007; 17: 185-93.

11 - Martin CCS, Melki JAD, Guimarães MA. Assessment of methods of homicides in a Brazilian city: a preliminary study. Forensic Sci Int 1999; 106:(1) 19-25.

12 - E-film ${ }^{\circledR}$ software, Merge Healthcare, Milwaukee, WI, USA. Available from: http://www.merge.com/efilm.asp.

Recebido para publicação em 27/08/2007

Aprovado para publicação em 13/05/2008 